\title{
THE DESIGN AND REALIZATION OF EMBEDDED WIRELESS DATA COLLECTION SYSTEM
}

\author{
Junfeng Zhang ${ }^{1}$, Feng $\mathrm{Yu}^{1}{ }^{1}$, Jichun Zhao ${ }^{1, *}$, Sufen Sun ${ }^{1}$ \\ ${ }^{1}$ Institute of Information on Science and Technology of Agriculture, Beijing Academy of \\ agriculture and forestry Sciences, Beijing, China, 100097 \\ * Corresponding author, Address: Institute of Information on Science and Technology of \\ Agriculture, Beijing Academy of agriculture and forestry Sciences, Beijing, China, 100097, \\ P. R. China,Tel: 13552902579,Email: zhaojichun123@tom.com
}

\begin{abstract}
The paper gives a method that greenhouse data collection and supervisory system based on GPRS (General Packet Radio Service) network is designed and implemented. It discusses chiefly a scheme, which uses ARM microcontroller to control GPRS module and make use of SMS(Short Messaging Service) to complete greenhouse data collection and supervision, and supplies a design program of the hardware and software, the communication way has better timeliness, without room limitation.
\end{abstract}

Keywords: GPRS, SMS, ARM, Data Collection

\section{INTRODUCTION}

The data collection and supervision in the greenhouse profession still is limited to the local area network with the 485 communication protocol. Although this way can meet the data supervision and processing, but the cover scope is small, the line maintenance quantity is big, the noise pollution in the electric power carrier will cause the correspondence not to be unreliable, moreover, intelligence supervisory system of greenhouse based on GPRS uses GSM/GPRS wireless network as the communication way, not only can solve the above problem, but also can widely be applied in other professions.

Please use the following format when citing this chapter:

Zhang, J., Yu, F., Zhao, J. and Sun, S., 2009, in IFIP International Federation for Information Processing, Volume 295, Computer and Computing Technologies in Agriculture II, Volume 3, eds. D. Li, Z. Chunjiang, (Boston: Springer), pp. 2031-2036. 


\section{SYSTEM PROFILES}

Intelligence supervisory system of greenhouse is a set of comprehensive computer system used in the upscale greenhouse, each greenhouse installs one, supervises the greenhouse warm target and so on humidity through sensors and carries on the automatic control to the greenhouse corresponding equipment to realize the climate parameter value which the greenhouse needs. Realizing one to multi-spot communication through the GPRS network, according to certain communication protocol, it may realize data gathering, the user forces to intervene the active state of the microcontroller and the equipment failure long distance reports to the terminal.

\section{SYSTEM REQUEST AND FUNCTIONAL DESIGN}

The system construction needs to meet and complete some basic long range data gathering and the transmission request, simultaneously, considering the demand of satisfying the market development and the economical dispatchment, having the dominative ability for input or output of switch quantity and prohibiting disturbance ability. According to the system demand, the function which the system needs to provide is as follows:

(1) data collection function: voltage or electric current standard signal which converted through the senor and bridge circuit turns the digital data after A/D transformation, These data may carry on the GPRS long-distance transmission through the monolithic integrated circuit by the short news way.

(2) data submission function on SMS: the control center may transmit the communication order to carry on the data collection, phone terminal number revision and to force to control the running state of switch quantity.

(3) control ability: the controller can dominate pad_pump 、evaginable window 、 fan and so on through supervising the temperature and humidity in the greenhouse.

\section{HARDWARE DESIGN}

\subsection{Hardware structure}

The remote data collection terminal is consisted of the sensor, the monolithic integrated circuit, the GPRS module and so on, it chiefly completes the environment data gathering and communicate with phone 

system

terminal device through certain protocol, its realization principle of hardware is shown in figure1.

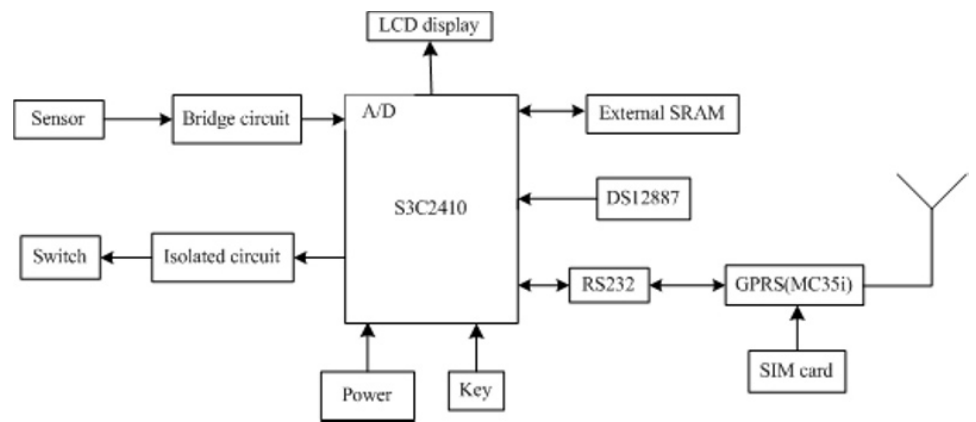

Figure 1

\subsection{Hardware explanation}

(1) CPU: The S3C2410 offers outstanding features with its CPU core, a 16/32-bit ARM920T RISC processor designed by Advanced RISC Machines. The ARM920T implements MMU, AMBA BUS, and Harvard cache architecture with separate $16 \mathrm{~KB}$ instruction and $16 \mathrm{~KB}$ data caches, each with an 8-word line length.

(2) Data collection: the Pt100 of temperature sensor can output $4 \sim 20 \mathrm{~mA}$ standard electric current through bridge circuit, the humidity sensor SA801 applies standard current output so that it does not carry on the non-standard electric quantity transformation.

(3)Store unit: data storage can deposit the data outside which gathered, it selects $32 \mathrm{~kb}$ static RAM, because of the battery in its interior, so, after the system power failure, it can preserve each gathering data and the user setting values.

(4) Clock part: it selects the DS12887 of American DALLAS corporation which arrives precisely the second and reads the current time for CPU.

(5) Serial port part: because GPRS module brings the RS232 level by itself, but MCU serial port is the TTL level, so, it should carry on the level transformation through the MAX232 chip.

(6) Man-machine contact surface: the data display part uses the LCD12864 liquid crystal, the keyboard response part uses the THINK82C79 control.

(7) Control output: in order to reduce the electromagnetic interference, the output unit uses the photoelectricity isolation technology, thus, selecting light pair MOC3061 and the silicon-controlled rectifier Z4090 chip. 


\section{SOFTWARE DESIGN}

\subsection{AT instruction}

For realizing SMS transmission, we must conform to AT instruction of the GSM communication, AT instruction which chiefly used in the article is shown in table1.

Table 1

\begin{tabular}{ll}
\hline AT instruction & Function \\
\hline AT + CMGF & Select SMS message format $(0=$ TEXT, 1=PDU $)$ \\
AT + CMGS & Send SMS message \\
AT + CMGR & Read SMS message \\
AT + CMGD & Delete SMS message \\
AT + CSQ & GPRS network exist? \\
\hline
\end{tabular}

For example, the article send short message by text model, the procedure transmission data as follows:

$\mathrm{AT}+\mathrm{CSQ}<\mathrm{cr}>$

+CSQ: 21,99//network exist

$\mathrm{AT}+\mathrm{CMGF}=1<\mathrm{cr}>/ /$ set text model AT + CGMS $=$ "phone number" $<$ cr $>$ send message $<$ ctrl $/ \mathrm{z}>$

condition. The SMS communication makes use of serial port interrupt characteristic of the MCU, it can reach the data collection and compulsion operation to the terminal device, its SMS procedure process is shown in figure2.

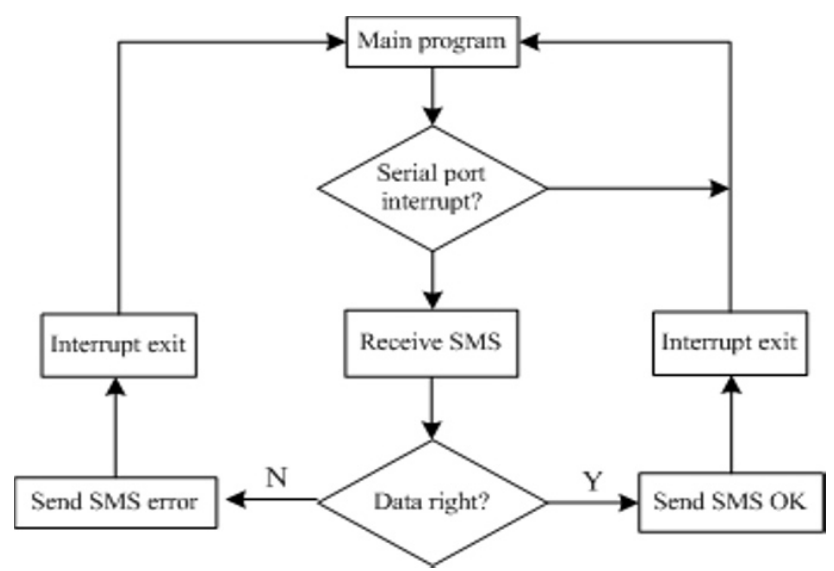

Figure 2 


\subsection{SMS subprogram}

(1) the subprogram that $\mathrm{MCU}$ receives AT instruction is follow: RECEIVE:LD AX,\#BDH;storage unit

LDB CL, \#06H; datacount

RECEIVE_1:DI

RECEIVE_2:LDB BL,SBUF JBC SP STAT,6,

RECEIVE_2 STB BL, [AX]+ DJNZ CL, RECEIVE_1 RET

(2) the subprogram that $\mathrm{MCU}$ receives AT instruction is follow: SEND:LDB CL, \#30H; data count// sen message to certain phone number+CMGS:199//sendback OK

\subsection{Program design}

The main program unceasingly compare with setting values of the user through gathering external environment condition, it will carry on the corresponding control command when satisfying the LD AX, $\# 00 \mathrm{H}$; data base address

$\begin{aligned} \text { SEND1:LDB } & \text { BL,\#00H } \\ \text { LDB } & \text { BL,DATA4[AX] } \\ \text { LDB } & \text { SBUF,BL } \\ \text { JBC } & \text { SP_STAT,5,\$ } \\ \text { INC } & \text { AX } \\ \text { DJNZ } & \text { CL,SEND1 } \\ \text { RET } & \end{aligned}$

\section{EXPERIMENT RESULT}

The user can edit the corresponding communication instruction which sent to the GPRS(TC35i) module via AT command orders, in order to manipulate the controller, for instance, one group operating results are as follows:

(1) access to the current temperature and humidity:

the back result which is shown on the cell phone by sending communication order LY1 is that: the temperature: $16.6^{\circ} \mathrm{C}$ and humidity: $26.6 \%$.

(2) open and off equipment: order LY2 which is sent denote that the equipment is ran ,on the contrary, it will close the one by the order LY3, the back result is: success, if the result do not return, it may the SIM card debt or equipment failures. 
(3) host set: by sending order LY4, in order to a cell phone always can controll single or multiple device, the back result : host lock.

(4) alarm on and off set: the back result on the cell phone is that the alarm setting is ran by sending order LY5, when it reach the alarm condition, it will send SMS to the host phone, on the contrary, it will close the alarm setting program by sending order LY6.

(5) targeted set: LY6+temperature number+humidity number of the order format is sent, for example, the order LY6 $+27+29$ denote that current goal temperature: $27^{\circ} \mathrm{C}$, humidity: $29 \%$, the precision only can reach integer here, the back result: targeted set success.

\section{CONCLUSION}

Along with the constant development of industrial modernization and new technologies evolvement, data collection and remote supervision is entering a phase of rapid development. Because of adopting GPRS netmwork, the system is a more advanced technology, it is easy to replace a lot of cablebased communications systems similar, whether for automatic meter reading system, or temperature measurements, environmental supervision, marine oil fields, have very good prospects for development.

\section{REFERENCES}

Aljadhai, A.; Znati, T.F.;"Predictive mobility support for QoS provisioning in mobile wireless environments", Selected Areas in Communications, IEEE Journal on , Volume: 19 Issue: 10 , Oct. 2001, pp. $1915-1930$.

Application of Image Gather Based on the S3C2410 Platform and Embedded Linux [M].Micro computer Information, 2006, 22

C. F. Grecas, I. S. Venieris, and D. -D. Koutsouris; "Uninterrupted Data Transmission over GSM and Application to Health.

Camargo J.R. An evaporative and desiccant cooling system for the air conditioning in humid climates. Journal of the Brazilian society of Mechanical Science and Engineering[J], 2005,27(3):243-247.

Egginton. Evaporative cooling saves energy costs. Engineering Technology[J],2005,8:39408(6):1667-1675.

Engineering and Manufacturing Co. Muskofgee, Oklahoma, 2003, 5 (7):727 741.

R. Pandya, "Mobile and Personal Communication System and Services", IEEE Press, ISBN $0-7803-4708-0,2000$. 